\title{
AC 2010-1537: IN THE EYE OF THE BEHOLDER: DEFINING AND STUDYING INTERDISCIPLINARITY IN ENGINEERING EDUCATION
}

\section{Lisa Lattuca, Pennsylvania State University}

David Knight, The Pennsylvania State University

David Knight is a doctoral student in the Higher Education Program and a graduate research assistant in the Center for the Study of Higher Education at Penn State. 


\title{
In the Eye of the Beholder: Defining and Studying Interdisciplinarity in Engineering Education
}

\begin{abstract}
The philosophical, practical, and empirical literature on interdisciplinarity reveals that there is considerable debate about what "counts" as interdisciplinary teaching and research. Decisions about which theories and definitions to adopt have implications for how scholars define interdisciplinarity, what educators believe constitutes interdisciplinary education, and for what researchers choose to include and exclude in studies of the development of students' interdisciplinary competence. In this paper we present data excerpts from six detailed case studies that reveal the many, varied, and often conflicting, definitions of interdisciplinarity used by engineering administrators and faculty members in discussions of undergraduate educational activities intended to develop students' interdisciplinary competence. These definitions-in-use do not always align with theory-based definitions of interdisciplinarity, and they did not neatly align with the conceptualization of interdisciplinarity that guided our study. In this paper, we discuss the methodological challenge that multiple, competing conceptualizations of interdisciplinarity (and multidisciplinarity) posed for the research team, focusing specifically on the question of whether to include or exclude from our analyses faculty and administrators' reports on learning activities if the conceptualization of interdisciplinary undergirding those activities was not consistent with our study definition. We discuss the substantive impact of different decisions and report how the team ultimately resolved this problem in a way that was methodologically and theoretically defensible. Finally, we present examples (from the case study sites) of learning activities that might not meet a strict theoretical definition of interdisciplinary educational activities but that might promote the development of interdisciplinary competence by building skills that contribute to that competence.
\end{abstract}

\section{Introduction}

Interdisciplinarity has been a topic of scholarly interest for several decades (see Klein, $1990^{1}$; Kockelmans, 1979² ; Lattuca, 2001 ${ }^{3}$; Organisation for Economic Co-operation and Development, $1972^{4}$; Repko, 2008 ${ }^{5}$ ), and engineering education researchers have recently begun to explore it as an educational approach at the graduate and undergraduate levels (e.g., Borrego, Newswander, McNair, McGinnis \& Paretti, 20096; Drezek, Olsen, \& Borrego, 20087 ; McNair, Paretti, \& Kakar, 2008 ${ }^{8}$; Newswander \& Borrego, 2009 ; Richter \& Paretti, 2009 ${ }^{10}$ ). Despite long-term and widespread interest in the topic, however, defining interdisciplinarity remains a conceptual and methodological challenge. For some, the definitional issue is obviated by choosing to study programs that are ostensibly interdisciplinary (e.g., the Interdisciplinary Graduate Education, Research and Training program). The philosophical, practical, and empirical literature on interdisciplinarity, however, reveals that there is considerable debate about what "counts" as interdisciplinary research and teaching. This continuing controversy is worth noting because how we define interdisciplinarity has implications not only for what we label as interdisciplinary education, but for what we choose to study and how we study it.

In this paper, we review the literature on this definitional dilemma as a prelude to a discussion of the definitional, methodological, and philosophical challenges that we faced in this study and 
that are likely to arise in other studies of interdisciplinary education. We document and illustrate these challenges though the use of data excerpts from six case studies conducted for Prototyping the Engineer of 2020: Conditions and Processes of Effective Education (P360 for short). Funded by a grant from the Curriculum, Course, and Laboratory Improvement (CCLI) Program of the National Science Foundation, the P360 research effort examines the curricular, pedagogical, cultural, and organizational features that support undergraduate engineering education that is well-aligned with the goals of the National Academy of Engineering's Engineer of $2020^{12}$. (An additional goal of this study is to identify educational practices that facilitate the success of women and minority students in engineering.)

Our findings reveal how engineering faculty and administrators implicitly and explicitly define interdisciplinarity. After demonstrating the different, sometimes conflicting, understandings of the term, we comment on the conceptualization of interdisciplinarity that guided our study and explain how we addressed the confusion in our analysis. We then present examples of learning activities (from the case study sites) intended to promote the development of interdisciplinary competence among undergraduate engineers. These examples illustrate how understandings of interdisciplinarity are translated into educational practices by faculty members, providing foodfor-thought for those interested in interdisciplinary education, but also for theorists and researchers interested in the development of interdisciplinary thinking and habits of mind.

\section{Defining Interdisciplinarity}

The literature on interdisciplinarity abounds with definitions and terms that seek to explain and categorize specific forms of interdisciplinarity - as well as with debates about these definitions and typologies. Some terms, such as interdisciplinarity and multidisciplinarity, are widely used but differently defined by scholars and apparently by practitioners who have little or no familiarity or interest in the scholarship on interdisciplinarity.

The term multidisciplinarity seems to have achieved wide usage in engineering as a result of the accreditation requirement that undergraduates in engineering programs develop the ability to "work in multidisciplinary teams" 12 . In the literature on interdisciplinarity, multidisciplinarity refers to attempts to bring the perspectives, tools, or insights of two or more disciplines to bear on a problem or to explain a phenomenon. According to Miller (1982) ${ }^{13}$, multidisciplinary approaches involve "the simple act of juxtaposing several disciplines" and make "no systematic attempt at integration or combination" (p. 9). In other words, multidisciplinarity concatenates disciplinary knowledge (Klein, 1996) ${ }^{14}$, or presents it in "serial fashion" (Richards, 1996) ${ }^{15}$, but does not synthesize or integrate the various elements of disciplinary knowledge into a cohesive whole. Those working in a multidisciplinary manner are presumed to behave as disciplinary experts, representing their discipline to others but not seeking to alter it in any way as a result of their interactions with experts from other disciplines.

Because the individual contributions of two or more disciplines can be discerned in these research and teaching projects, multidisciplinary work is often criticized as a 'false' interdisciplinarity. Newell $(1998)^{16}$, for example, classified multidisciplinarity as partial interdisciplinarity because it only includes one element of interdisciplinarity, that is, the perspectives of more than one discipline. Like Miller, Newell excludes multidisciplinary efforts 
from the category of interdisciplinarity because it does not attempt to integrate disciplinary perspectives.

Interdisciplinarity has often been characterized - and implicitly defined - as borrowing; researchers or instructors borrow concepts, theories, or methods from one discipline for use in another. Research approaches that borrow methods have been called method interdisciplinarity or instrumental interdisciplinarity (see Klein, 1993) ${ }^{17}$; the term cross-disciplinarity has been used to describe both research and teaching approaches that borrow either theories or method (Lattuca, 2001) ${ }^{3}$. This term is intended to be broader than either method or instrumental interdisciplinarity. Miller (1982) ${ }^{13}$ defined cross-disciplinarity as an effort to connect and combine ideas across disciplinary boundaries and cited research areas such as criminal justice and area studies as examples of this form of interdisciplinarity. In contrast, Kockelmans (1979) ${ }^{2}$ argued that cross-disciplinary scholarship sought to develop or discover "encompassing frames of reference" (p. 141).

Some scholars have argued that neither instrumental interdisciplinarity nor cross-disciplinarity is a true form of interdisciplinarity. Heckhausen (1972) ${ }^{18}$ considered instrumental borrowing of methods from another discipline to be "pseudo interdisciplinarity," and Jantsch (1972) 19 argued that cross-disciplinarity implied a "brute force" approach to "reinterpret disciplinary concepts and goals...in light of one specific (disciplinary) goal and to impose a rigid polarisation across disciplines" (p. 107).

In contrast, 'true' or 'full' interdisciplinarity has been defined as the integration of disciplinary contributions so that the separate contributions of the individual disciplines are obscured. Two well-known proponents of interdisciplinarity, Julie Thompson Klein and Bill Newell, define interdisciplinarity as "a process of answering a question, solving a problem, or addressing a topic that is too broad or complex to be dealt with adequately by a single discipline or profession... and draws upon disciplinary perspectives and integrates their insights through construction of a more comprehensive perspective" (1997, p. 393-394) ${ }^{20}$.

Although integration is favored as a marker of interdisciplinarity (see Repko, 2008 ; Klein \& Newell, $1997^{20}$; Newell, $1998^{16}$ ), there is not complete agreement on the role of integration in interdisciplinary work. A few scholars argue that defining interdisciplinarity in this way excludes some individuals - particularly those working in fields in the humanities such as women's and ethnic studies, cultural studies, literary analysis - from consideration. Rather than building on or synthesizing disciplinary methods, concepts, or insights, faculty in these fields may view interdisciplinarity as part of a larger project to redefine knowledge.

\section{The Role of Integration in Interdisciplinarity}

In a volume entitled Interdisciplinarity: Problems of Teaching and Research in Universities, the Organisation for Economic Co-operation and Development (OECD) used the adjective form of the word - interdisciplinary - to describe "the interaction among two or more different disciplines. This interaction may range from simple communication of ideas to the mutual integration of organising concepts, methodology, procedures, epistemology, terminology, data, and organisation of research and education in a fairly large field" (1972, pp. 25-26) ${ }^{4}$. This 
definition suggests interdisciplinarity exists on a continuum. On one end of this continuum is the informal communication of ideas, such as what might occur in a conversation between colleagues from different disciplines; on the other end is formal collaboration, such as research or teaching teams comprised of faculty from different disciplines. This definition does not insist that the disciplines are central to interdisciplinarity nor does it establish a fixed point - such as integration - at which interdisciplinarity occurs. The integration of disciplinary components is one potential outcome of interdisciplinary work, but according to this definition, it is not the only criterion for interdisciplinarity.

Repko $(2008)^{5}$ argues that interdisciplinarity "should be defined in terms of integration" and that "the disciplines themselves are the necessary preconditions for and foundation of interdisciplinarity" (p. 123). The task in an interdisciplinary project is to "identify the perspective of each discipline and interdiscipline ${ }^{i}$ and their defining elements relevant to the problem [to be solved]" (2008, p. 122). This process of achieving integration, according to Klein (1996, p. $221)^{14}$, requires identifying, evaluating, and rectifying differences between disciplinary insights. The OECD definition, although it differs from the definition above, similarly describes a process rather than an outcome, and this process-oriented definition has gained ground in recent years.

\section{From Interdisciplinarity to Transdisciplinarity}

The term transdisciplinarity has been around for many years but has changed meanings numerous times. The current iteration is particularly interesting from an engineering standpoint. Early discussions of transdisciplinarity conceived of it as the ultimate coordination among the disciplines. Piaget $(1972)^{21}$, for example, imagined a "total system without any boundaries between disciplines (p. 138). Some, however, rejected these approaches at unification: Kockelmans (1979) ${ }^{2}$ argued that these definitions presuppose structuralist forms or general systems theory. Kockelmans $(1979)^{2}$ and Miller (1982) ${ }^{13}$ also acknowledged that supporters of transdisciplinarity held a number of different epistemological views: one camp sought to develop holistic, encompassing conceptual frameworks to replace disciplinary approaches, while another focused on developing a unified world view grounded in the disciplines (Kockelmans, 1979) ${ }^{2}$.

Recently, transdisciplinarity has been used to describe a form of knowledge production in which researchers from a wide range of disciplines work together with stakeholders outside the academy (Hirsch Hadorn, Hoffmann-Riem, Biber-Klemm, Grossenbacher-Mansuy, Joye , Pohl, Wiesmann \& Zemp, 2008) ${ }^{22}$. Gibbons, Limoges, Nowotny, Schwartzman, Scott, and Trow $(1994)^{23}$ argued that transdisciplinary forms of research are not intended to create new disciplines or interdisciplines. Rather, they are problem-centered activities:

A transdisciplinary mode consists in a continuous linking and relinking, in specific clusterings and configurations of knowledge...brought together on a temporary basis in specific contexts of application...The transdisciplinary mode of knowledge production described by us does not necessarily aim to establish itself as a new, transdisciplinary discipline, nor is it inspired by restoring cognitive unity. To the contrary, it is essentially a temporary configuration and thus highly mutable.

This iteration of transdisciplinarity may describe the problem-focused work of practicing engineers who seek to solve specific problems under specific conditions; such solutions may or may not be effective in other settings where different conditions and constraints are at work. 
Transdisciplinarity acknowledges that particular social, cultural, environmental, political, economic, and other contexts can shape problem solutions and that these solutions, because they affect individuals and communities, must include consideration of these contexts - an outcome emphasized in the ABET EC2000 accreditation criteria for undergraduate engineering programs.

\section{Empirical Evidence, Normative Choices}

The previous discussion of the definitions of interdisciplinarity and its synonyms reveals that decisions about which activities, processes, and outcomes to label as interdisciplinary - or multidisciplinary, cross-disciplinary, or transdisciplinary - are typically normative (based on values) rather than being empirically based or data-driven. Definitions devised by scholars do not neatly align with one another, nor with the definitions-in-use of practitioners; Lattuca (2001) ${ }^{3}$ demonstrated that faculty members' labeling of their work as interdisciplinary did not neatly conform to the definitions prevalent in the literature. Accordingly, when we began our research on how engineering programs develop interdisciplinary competence, we expected to encounter some confusion in these terms. The principles of good research practice, however, suggest that clear definitions are needed to guide data collection and analysis. By holding to a clear definition of interdisciplinarity, we hoped to alleviate any problems we encountered as we talked with study participants and analyzed our data.

Given the focus of our paper, we include information on how we defined interdisciplinarity here, as well as in our methods section. Following the trend in the literature, we defined interdisciplinarity as "a process of answering a question, solving a problem, or addressing a topic that is too broad or complex to be dealt with adequately by a single discipline or profession.... and [that] draws upon disciplinary perspectives and integrates their insights through construction of a more comprehensive perspective" (Klein \& Newell, 1997) ${ }^{20}$. Furthermore, cognizant of ABET's EC2000 Critierion 3.d which requires engineering programs to develop students' abilities to work in multidisciplinary teams, we further defined the terms multidisciplinary and interdisciplinary. Multidisciplinary teams (or courses or projects) included participants from different fields within the larger discipline of engineering. In contrast, interdisciplinary teams or projects included engineers as well as individuals from outside engineering (e.g., students or faculty from business, education, chemistry, or economics).

Despite our specification of a definition, faculty and administrators at the case study institutions used a plethora of terms and definitions, raising an important methodological question. Should we exclude discussions of educational practices and activities that did not meet our definition? How we answered the question of what to count as "interdisciplinary" would have a substantive impact on our analysis. If we prioritized the extant theoretical definitions in the literature (which guided the study) over the definitions-in-use of our study participants, we would eliminate from consideration of interdisciplinary teaching activities that 1) were not clearly focused on the integration of disciplinary knowledge, and 2) designed solely for engineers.

This question of what to "count" as interdisciplinary is philosophical, as well as methodological. Qualitative research approaches typically seek to respect the "emic", that is, participants' understanding of events and phenomena. Although they may rely on a priori and/or theoretical definitions and even conceptual frameworks, qualitative researchers in general believe it is 
important to understand an idea, such as interdisciplinarity, as their study informants understand it. Some qualitative researchers argue further that privileging theoretical understanding over participants' understandings defeats the purpose of qualitative research, whose goal and strength is to understand the meanings that study participants make of the worlds (Bogdan and Biklen, $2006^{24}$; Denzin and Lincoln, $2000^{25}$ ). Others would counter that qualitative researchers can include participants' perspectives in their work without having to agree with them; presenting participants' understandings as they both align and conflict with other perspectives accurately reflects the complexity of the world in which we live. Our data obliged us to consider different options.

The variety of understandings we encountered in this study complicated the research project but eventually led us to a more nuanced way of thinking about how to study interdisciplinary competence in engineering education. By presenting data from the case studies that demonstrate the variety of understandings of interdisciplinarity of our study participants and examples of the educational approaches they used to build students' interdisciplinary competence, we demonstrate how this evolution in our thinking occurred and explore its significance for researchers and educators.

\section{Methods}

The P360 study took its inspiration from the National Academy of Engineering's report entitled, Educating the Engineer of 2020: Visions of Engineering in the New Century ${ }^{11}$, which identifies the attributes and skills engineers will need to maintain U.S. technological and economic competitiveness. The NAE report envisions the workplace of the near future as one of dynamic technological change that requires an understanding of complex societal, global, and professional contexts. Among the attributes described by the Engineer of 2020 report are strong analytical skills, practical ingenuity, creativity, communication competencies, lifelong learning, agility, flexibility, resilience, high ethical standards, professionalism, business and management skills, and leadership skills. Discussions of these attributes strongly suggest that the engineer of the future must be able to work effectively with others on projects that require interdisciplinary thinking and skills.

The goal of the P360 study is to identify and analyze the curricular, pedagogical, cultural, and organizational features that support engineering education that appear to be aligned with the goals of the Engineer of 2020. The study concentrates on three attributes that appear to be central to the goals of the engineer of 2020: design and problem-solving skills, interdisciplinary competence, and contextual competence. The study is also examining institutional and educational practices and programs that contribute to the success of women and underrepresented minority students in engineering programs. In this paper, we focus exclusively on interdisciplinary competence.

\section{Site Selection}

The research team used a nationally representative dataset developed for the Engineering Change study (Lattuca, Terenzini, \& Volkwein, 2006) ${ }^{26}$, which assessed the impact of the implementation of ABET's outcomes-based EC2000 accreditation criteria, to empirically select 
six case study sites. Using a variety of survey items from the student survey developed for the Engineering Change study, the team created a proxy for interdisciplinary competence that was used to identify programs and institutions in which graduates reported both a high level of ability in working on multidisciplinary teams (EC2000 Criterion 3.d) and understanding the impact of engineering solutions in a global and societal context (EC2000 Criterion 3.h).

The team presented the top ten institutions for discussion at a meeting of its National Advisory Board. In consultation with the Board, they reduced the set of institutions to the five that exhibited superior performance on the focal learning outcomes and/or in recruiting and graduating women and underrepresented students: Arizona State University (ASU), Howard University, Massachusetts Institute of Technology (MIT), the University of Michigan (UM), and Virginia Tech (VT). Upon the recommendation of its National Advisory Board, the research team added Harvey Mudd College (HMC), an institution not included in the Engineering Change dataset, to the study in recognition of its national reputation for graduating engineers with superior design and problem-solving skills.

\section{Data Collection and Analysis}

In 2007-08, the research team divided into three smaller teams, each comprised of four to five faculty and graduate research assistants from the fields of engineering and education. Each team was responsible for data collection and reporting for two case studies. Data collection relied on multiple sources of evidence: personal and group (or focus) interviews with faculty, administrators, students, and professional staff (e.g., student support services); observations of classes and events (e.g., Projects Day), archival records (e.g., meeting minutes), and other artifacts (websites, documents). Triangulation of these data sources enabled corroboration of facts and events at each case study site. In addition, the use of multiple investigators for each site (each team included at least one faculty member from engineering and one from education), contributed to construct validity (Yin, 2009) ${ }^{27}$.

Each case study site was visited at least twice to identify and study the factors shaping each institution's performance. The full team developed a set of protocols for different groups of interviewees for the first set of case study site visits. The first visit examined organizational and curricular structures and policies identified from websites, engineering education literature, and discussions with academic administrators at each site. During this site visit, researchers identified additional individuals and educational experiences to be studied more intensively during the second site visit. For the subsequent visits, the teams customized interview protocols for the various groups of participants, for example, creating interview questions focused on academic support systems for undergraduates for student services staff, protocols to guide data collection on new minors in entrepreneurship or manufacturing design, and other interview protocols for students in various academic and co-curricular activities.

Data collection was completed by fall 2008. Personal and group interviews were fully transcribed and entered into Nvivo, a software program that supports the management and analysis of qualitative data. Each team analyzed the data from the two case studies it conducted. Coding and preliminary analysis of data began when each team completed its visits. Case study reports were shared with key informants at each site to a) ensure accuracy in reporting, b) enable 
subjects who requested the opportunity to review their direct quotations (as specified in the informed consents); and c) to further enhance construct validity by soliciting participants' viewpoints (Yin, 2009) ${ }^{27}$.

During fall 2009 and spring 2010 the research teams completed their analyses and case study reports, in preparation for a cross-case analysis in late summer 2010. . This final analysis will identify common themes across the six case study sites.

\section{Defining Interdisciplinarity for the P360 Study}

Although a proxy for interdisciplinary competence was used to empirically identify the case study institutions, the research team developed a stricter definition to guide this research. Given the inspiration for the study, the team first considered the understandings of interdisciplinarity in engineering practice presented in the NAE's Engineer of 2020 reports. The Engineer of $2020^{11}$ specifies that engineers must be able to synthesize information from a broad range of disciplines and understand the constraints of social systems as well as the economic, legal and political constraints of an engineering design solution. The P360 team termed this composite of knowledge and skills "interdisciplinary competence."

To ensure the teams had the same understandings of the three "focal" objects of study (of which interdisciplinary competence is one), and built on existing research and theory, the graduate student researchers conducted literature reviews for each focal outcome. These became the basis for written descriptions of the competencies, which were discussed by the group to further refine their understandings of the concepts.

The team's working definition of interdisciplinary competence focused on engineering students' abilities to understand and utilize knowledge and modes of inquiry drawn from disciplines other than engineering. Specifically, interdisciplinarity is defined as a perspective, practice, or problem-solving approach that utilizes modes of inquiry drawn from one or more disciplinary or nondisciplinary perspectives. Interdisciplinary competence is evidenced by an appreciation of various perspectives and an ability to incorporate and evaluate multiple disciplinary approaches in problem-solving. Interdisciplinary competence also includes the ability to assess the strengths or weaknesses of one's own disciplinary perspective, as well as to recognize shared assumptions, skills, or knowledge among disciplines.

Using this definition as a guide as they conducted their site visits, each of the three subteams explored how undergraduate engineering programs build students' interdisciplinary competence. The three teams found a variety of curricular and co-curricular arrangements intended to cultivate interdisciplinary competence, including core curricula rooted in a systems perspective, design courses and teams, elective courses, minors, and co-curricular opportunities, including undergraduate research opportunities and student clubs.

\section{Limitations of the Study}

Six institutions were purposefully selected for this study because data analysis indicated that they outperformed a set of nationally representative institutions on one or more of the selection 
criteria. Because these institutions were not randomly chosen, the study findings are not generalizable to the national population of engineering schools. The goal of the study is instead to provide information on the curricular, instructional, and organizational practices that appear to provide students with opportunities to develop a specific set of learning outcomes (including interdisciplinary competence).

Time and financial limitations limited the amount of time that could be spent in data collection at each of the six study sites; the P360 study thus relied primarily on interviews with faculty, administrators and students to explore the curricular, instructional, and organizational practices that promoted the development of the targeted learning outcomes. The research teams conducted limited observations of classrooms, labs, and out-of-class experiences. Additional observations might have provided deeper understanding of the nominally interdisciplinary activities noted by faculty, administrators, and students in the case studies.

Despite these limitations the team was able to develop detailed descriptions of learning activities based on interviewees' discussions, ask questions when clarifications were needed, and triangulate faculty, administrator and student level data for many of learning activities to develop deep understandings of the educational practices in place and the linkages among these.

The P360 study was not designed to collect evidence of student learning, so it cannot establish the effectiveness of particular learning activities. A companion study, Prototype to Production: Conditions and Processes for Educating the Engineer of 2020 (P2P), however, will provide quantitative assessments of students' learning outcomes for each of the case study institutions, as well as for a stratified random sample of 26 additional institutions. The data from the P2P study will be analyzed to determine if the curricular, instructional, and organizational practices and conditions identified in the case study institutions produce superior learning outcomes in the national sample.

\section{Findings}

The findings section of this paper is divided into two major parts. Part I reveals the many different ways that study participants - primarily faculty and administrators - defined interdisciplinarity both explicitly and implicitly through descriptions of their educational programs and practices. This section begins by presenting informants' discussions of multidisciplinarity, followed by their understandings of interdisciplinarity. We close this section with an examination of other terms that faculty and administrators used as synonyms for interdisciplinarity or to suggest extensions of the concept. In Part II, we present examples of interdisciplinary learning activities from the case study sites to explore the educational approaches intended to promote interdisciplinary competence at the case study institutions. Reflecting on our findings from Part I allows us to explain the decision rules that guided our choice of examples for this paper - and that will guide the analyses that will follow.

\section{Part I: The Multiple Meanings of Interdisciplinarity}

Though we did not specifically ask interviewees for their personal definition of the term, we were able to infer their characterization of the concept from their comments about undergraduate 
education and research. These "implied definitions" reveal a wide variety of understandings of the most widely used terms, multidisciplinarity and interdisciplinarity.

\section{Multidisciplinarity}

Faculty members and administrators have numerous understandings of the term multidisciplinarity, an interesting finding since it calls into question the clarity with which programs understand ABET Criterion 3.d, which specifies that undergraduates must develop the ability to "work in multidisciplinary teams." As previously noted, our research team defined multidisciplinarity as occurring within the confines of engineering; a multidisciplinary team would include engineers from different disciplines, but not from fields outside engineering. Several interviewees shared this understanding, and faculty members across the research sites described introductory engineering courses as multidisciplinary because they include students from all engineering majors.

Similarly, study participants often described capstone courses in this manner. For example, a Harvey Mudd College faculty member's description of a "Clinic" project suggested that he uses multidisciplinarity as we defined it, referring to teams of students from within engineering:

And clinic is where students have this, usually multidisciplinary problem that they are trying to deal with. So they draw from, I mean today you saw the mechanical engineering, structurally how do we make this not fall off our plane, and electrically, how do we make it communicate to the down station or base station. So I think that is it, they have to use, they have to draw on all of the disciplines.

Similarly, a Virginia Tech faculty member defined multidisciplinarity as "this whole idea of functioning interactively with a large group in a work environment" in referring to broad engineering design. Another faculty member demonstrated the within-engineering understanding of the term when commenting on how departments sometimes bend the definition of multidisciplinarity to meet ABET requirements by classifying teams that include students with different specializations within the same field (e.g,, electrical engineering) to be multidisciplinary. The contention that integration between sub-disciplines within an engineering department constitutes multidisciplinarity may be suspect to some, but it is consistent with the terminology we adopted for this study.

Another group of interviewees referred to collaborations with departments outside engineering in discussing multidisciplinarity. For example, a different Virginia Tech faculty member indicated that a multidisciplinary design environment included "business, marketing people; industrial engineers, architects maybe; psychologists; communications people." In listing this array of fields, he distinguished his understanding of multidisciplinarity from that of the research team (as well as some of his colleagues) by defining a multidisciplinary team as one that includes students in fields other than engineering. An MIT faculty member similarly listed a variety of academic departments in explaining the need to structure curriculum to ensure that students receive proper multidisciplinary training:

On top of that MIT always did this but they emphasis has grown in the last ten years, we want the students to be much more well rounded, rather than being so narrowly focused on a particular topic. That means our undergraduate curriculum requires that the students take 
humanities subjects, a minimum number of humanities subjects, perhaps take a foreign language or two, do undergraduate research. It is purely voluntarily but a lot of students do this. So the whole issue of volume of information, multi-disciplinarity of information, how do we package that within the school is a tricky issue.

A second faculty member from MIT shared this sentiment, arguing that students should be exposed to fields outside the limits of engineering.

An ASU professor described a multidisciplinary team functioning like a corporation taking a problem from production through implementation:

And I would love to even see a situation where people from the business school are incorporated. So really get a multidisciplinary team so it's kind of like a small corporation, where you're going from a business plan to the implementation, the marketing, all of that stuff. And that's really something that I think could be very unique and could really teach our engineering students how to interact with people other than chemical engineers.

Another ASU faculty member envisioned a similar "multidisciplinary" team that incorporated engineering, business, and law. Along the same lines, an HMC faculty member noted that "when our teams are comprised of both physics majors and engineering majors, and they work very well together, it really presents as close to the ideal multidisciplinary experience as you can imagine."

The team found considerable inconsistency among interviewees, sometimes in the same institution, in ideas about what constitutes a multidisciplinary team. Perhaps the most interesting interpretation of multidisciplinarity came from a faculty member who described first-year student teams as multidisciplinary since first-year students had not yet declared a specific major and because they contributed a variety of skills. This interpretation is a stretch if we consider the disciplines to be the foundation of interdisciplinarity, but it demonstrates the malleability of the definition of multidisciplinarity. A number of our data excerpts are consistent with the definition that guided our study, but a greater number of faculty defined multidisciplinarity in a way that was better aligned with our definition of interdisciplinarity, which specified interactions with individuals or activities based in non-engineering fields.

\section{Interdisciplinarity}

We found a similar inconsistency in the interpretation of the term interdisciplinarity. Several respondents provided examples of within-engineering collaboration and learning that our team would have classified as multidisciplinarity. A Howard University faculty member suggested that a goal for an engineering program should be "to introduce students to the various forms of engineering, to let them see the interdisciplinary opportunities." An MIT professor shared this within-engineering perception of interdisciplinarity in explaining why departmental boundaries in engineering do not impede interdisciplinary collaboration among faculty or students at the Institute.

In contrast, faculty members at Harvey Mudd College argued that the existence of a single department of general engineering created an inherently interdisciplinary environment. One faculty member said the institution "maintained a very broad, very interdisciplinary situation 
within engineering." According to our working definition, interdisciplinarity would not occur within the confines of engineering.

Several interviewees labeled coursework that introduced topics from various engineering departments as interdisciplinary. A Virginia Tech professor contended that one way to increase interdisciplinarity would be to implement an introduction to engineering disciplines course so "every single student knows kind of sort of what Chem Es think about, what are the hot topics." At ASU, a faculty member described an interdisciplinary capstone course in which engineers from different departments would work together to solve problems:

Let's say any given semester there might be five or six capstone courses offered. And Course A might accept students from any of four different majors, for example. So we want to have more interdisciplinary capstone courses. That is one thing the students are asking for. They're saying... I'm kind of tired of working with a bunch of electrical engineers. Can we have more opportunities to work on things where you actually need an electrical and a mechanical and a something-other engineer?

Likewise, a Howard professor described engineers-only interdisciplinary teams in a projectbased course and the rationale for the grouping:

We assumed "Okay, if there is a civil engineer, that civil engineer chose civil engineering because that student had a certain interest in those types of things. A mechanical engineer might have different interests, so maybe even though they haven't really taken any courses in their major, their interests would be brought together in a certain way, and they would work together in a team, and maybe bring something different to the teams." So that was the idea of the interdisciplinary teams.

Another HU faculty member noted that the interdisciplinary nature of nanosciences makes it difficult to determine the specialization of the engineering faculty working on these projects.

In summary, multiple engineering faculty members across research sites implicitly defined interdisciplinarity as a collaboration of individuals who think and approach problems differently or add unique perspectives and expertise to a team. In this sense, interdisciplinarity can occur solely within the engineering context.

Other study participants defined interdisciplinarity as the integration of engineering and other external fields, corresponding to our team's definition. For example, a Virginia Tech faculty member referred to a program as inherently interdisciplinary because students enrolled from more than one college. An ASU professor considered a research project interdisciplinary because it incorporated faculty from departments such as planning, geography, computer science, and engineering. Likewise, another ASU faculty member categorized work as interdisciplinary because it involved mechanical engineers, biologists, geologists, and hydrologists. A third ASU interviewee portrayed a new program's interdisciplinary aspects as "focusing on the interaction between physics, geography, and biology to tie the interactions between physical sciences together." Connecting business and international studies to engineering was the example provided by a University of Michigan professor. Another Virginia Tech faculty member defined a solar house project as an interdisciplinary project because it incorporated a cross-section of academic disciplines, for example, building and construction, computer engineering, and architecture. He further noted that a solar house with sustainable components could pull in 
students with additional perspectives. This kind of team presence, he argued, was not only a real world application but a cutting edge solution as well.

An administrator from Howard University discussed an interdisciplinary capstone course that included students from both engineering and business, pointing to the interaction of engineering students with non-engineering students as the source of learning in this setting. In addition, he described how this amalgamation of majors created more well-rounded students:

At the senior year, as in most engineering programs, we have a capstone design course and it too can be interdisciplinary. We have had students in mechanical engineering, electrical engineers, chemical engineers, students from school of business as well as students from our arts program because they were given a project that required, you had to do a prototype of it, design and build a prototype of it, so we think that those kinds of experiences helped our students to understand the importance of interacting and understand the importance of being a complete person, and so we think that is kind of important to do.

These characterizations of interdisciplinarity are markedly different from those that are limited to within-engineering collaborations. Incorporating knowledge and techniques from fields external to engineering appears to introduce a new set of skills and learning opportunities to students.

How we define terms is significant, then, not only in terms of what we "count" as interdisciplinarity, but in terms of expected learning outcomes for students.

Our research suggests a wide variation in the definition among faculty and administrators within and across six prominent engineering institutions. Interviewees tended to use interdisciplinarity and multidisciplinarity interchangeably; both words were used to indicate projects or collaborations strictly within engineering as well as those with fields external to engineering. A Virginia Tech faculty member's response to an interviewer's question about interdisciplinary competence summarizes our findings of the wide variance in definitions among members of the engineering community: "So when you say interdisciplinary, do you mean among engineering or among science and math and engineering or...?" Our findings suggest that the engineering education community has yet to reach consensus on what exactly interdisciplinarity entails.

\section{Synonyms for Interdisciplinarity}

A number of interviewees across our case study sites referred to courses that included engineers from different disciplines as "cross-disciplinary." These included first-year and capstone courses. A faculty member at ASU commented on the mix of students in "Engineering 101type" courses: "It's pretty common throughout Engineering to have an entry-level engineering course where you get cross-disciplinary engineers together, and you get different aspects from them." At Virginia Tech, a faculty member suggested similar benefits of what he described as cross-disciplinary design courses in which students are challenged to explain to engineers in other fields why particular design decisions should be implemented.

Another ASU faculty member introduced the term "transdisciplinary" in a discussion of a set of project-based courses, again referring to courses in which students from different engineering fields work together. He seemed, however, to use the term as a synonym for interdisciplinarity. 
Here we're very strong on transdisciplinary activities...interdisciplinary...we do our best to make sure that all of our students have an opportunity to work on a group that has folks from different majors. In the computing program... we don't have a capstone in computing. The capstone is really an experience that is spread across the last two years where students participate as their capability levels increase... in different roles in ongoing projects.

As we found with the terms inter- and multidisciplinary, conflation of terms like interdisciplinary and transdisciplinary also occurred across the research sites. For example, a faculty member from Howard used the terms interdisciplinary, multidisciplinarity, and transdisciplinary to describe research activities in the nanosciences without making any clear distinctions among them. He described a new graduate program as interdisciplinary because it involved a number of disciplines inside and outside engineering and had no college or departmental home. Participants in this program also worked closely with physicians at the independent Barrow Neurological Institute. Although this faculty member claimed that the partnership created the interdisciplinarity program, some would suggest the term transdisciplinary better captures the nature of this kind of collaboration, which extends beyond the walls of the university and into the community. Others would suggest that the term transdisciplinarity should be reserved for research that serves local needs by solving particular, local problems; this kind of research may contrast sharply with research intended to produce generalizable knowledge (which has been a hallmark of academic research in scientific fields).

The data excerpts we have presented raised methodological and philosophical issues about what to "count" as interdisciplinarity. In Part II of our findings, we discuss how the research team addressed these issues and then present illustrations of activities, again taken from our case study data, which may lead to the development of interdisciplinary competence.

\section{Part II: Developing Multi- and Interdisciplinary Competence}

The definitions that guided this research distinguished multidisciplinarity from interdisciplinarity, specifying that interdisciplinarity required the integration of knowledge and skills from engineering and non-engineering disciplines, whereas multidisciplinarity referred to the integration of knowledge and skills of different engineering disciplines. As we demonstrated in the first part of this paper, however, the use of these terms varied widely among engineering faculty, administrators and students at the case study sites. Previous research and experience suggests that the research sites are not unique in this regard.

As noted in our literature review, a number of recent academic discussions of interdisciplinarity view its endpoint as the integration of knowledge and skills from one or more disciplines. To develop interdisciplinary competence, some suggest students must develop an awareness of disciplines as scholarly communities as well as bodies of knowledge and appreciate the contribution that different fields can make to understanding phenomena or solving problems (see Repko, $2008^{5}$; Klein and Newell, $1997^{20}$ ). Thus, to develop interdisciplinary competence, one must first develop disciplinary understanding.

A number of scholars argue that though the foundations of interdisciplinary competence are awareness and appreciation of other disciplines and their perspectives, individuals seeking interdisciplinary solutions to problems must also recognize the limitations of the disciplines, at least in terms of their abilities to address particular problems (e.g., Repko, 2008) ${ }^{5}$. Moreover, 
since disciplinary perspectives are not always commensurate, the process of integrating those perspectives requires individuals not only to identify, but to evaluate and rectify disciplinary concepts, theories, insights, and so on (Klein and Newell (1996) ${ }^{20}$. Interdisciplinarity should be understood, therefore, as a process as well as a product of inquiry. This process orientation further suggests that, from a research perspective, judging educational activities in terms of whether they stress or produce integration of disciplinary perspectives is inadvisable. Excluding the multidisciplinary interactions of students in engineering teams, for example, would effectively limit our ability to see how the development of an appreciation for different engineering fields might contribute down the road to the development of integrative skills.

In the next section of this paper, we provide examples of educational activities intended to foster interdisciplinary competence - whether multi or interdisciplinary - because these have the potential to contribute to the development of interdisciplinary competence by raising students' awareness of disciplines and fields within and outside engineering and/or help them make connections across disciplines and fields.

\section{Building Interdisciplinary Competence: Curricular, Instructional, and Co- Curricular Learning}

Faculty and administrators across the case study sites commented on the inherent interdisciplinarity of particular fields of study. At Howard, materials science was included in the same sentence with specializations such as nanotechnology. At HMC, an engineer noted, "Materials tends to be fairly multi-disciplinary as it is, because you do everything from surface science to metallurgy." At ASU, a faculty member considered aerospace engineering to be interdisciplinarity because working on an aircraft design ties together multiple disciplines. At MIT, a chemical engineer reported that certain chemical engineering problems are naturally linked to biology and bioprocess engineering. At Harvey Mudd, two civil engineers talked about interdisciplinarity as a necessity in their field because of the social impacts of the work that civil engineers do.

In our interviews, we asked faculty and administrators to move beyond such general statements to specific examples of courses, instructional approaches, and co-curricular activities that fostered interdisciplinary competence in students. In response, participants discussed a number of educational opportunities, both inside and outside the classroom, which they believed promoted interdisciplinary competence.

We include these examples here, regardless of whether they were termed interdisciplinary or multidisciplinary or whether consistent with our stated definition. This is not simply an attempt to respect participants' understandings of the terms; rather we present these examples because they provide students with opportunities for multi- or interdisciplinary learning, which assist them in the development of interdisciplinary competence. These opportunities could include learning about other disciplines, working with representatives of other disciplines, learning the limitations of their own disciplines, appreciating the value in other disciplinary perspectives, and eventually, perhaps, integrating disciplinary perspectives.

\section{Curricular Approaches to Interdisciplinarity}


Though most of the case study institutions provided students with opportunities in at least some of their engineering programs to work with students in other engineering and non-engineering disciplines, the curriculum at Harvey Mudd was notable for a more foundational approach. HMC offers one engineering degree in general engineering, and all HMC students, regardless of major, take the same required core courses in the sciences, social sciences and humanities. Among the required courses is a sequence of systems courses grounded in transformation-based mathematics, which one professor described as "the universal language for learning" in engineering. It is, he explained, "the thing that allows you to be able to talk to the electrical engineer, the mechanical, the civil, the Russian engineer, the Greek engineer, the Latin engineer. It gives you, it opens up everything for you."

When asked if he thought students learned to think in interdisciplinary ways at HMC, another engineer pointed to the systems sequence:

That is one class where we bring all of the various engineering disciplines together. So we tie in mechanical, electrical, thermal, hydraulic, and so on and so forth. In E59 we really try to show them the analogy between all of these different systems, and then in 101 and 102 -I have never taught those classes but I know in 101 and 102 they do a lot of transforms - so they have Fourier transform, discrete transform, Laplace transforms. So we show them all of the tools that they can use to help solve all of these different problems. Then in 102, I think they spend a lot of time in talking about controls: how control can be used to control problems in mechanical and chemical and electrical engineering and the fundamental concept behind it, it is all the same. So all you have is a plan that would be pertinent to the field, but everything else is going to be exactly the same. So we try to emphasize the fact that what they have learned in systems class can be applied to all fields of engineering.

The systems courses at HMC shows students how what they are learning can be applied across engineering disciplines, thus creating awareness of the similarities among fields rather than their differences alone. An HMC faculty member who has taught the systems courses discussed the focus on analogous systems:

... it used to be that you couldn't simulate this stuff on a computer. So if I wanted to be able to study a dam, instead of building a dam, I would build a circuit, and then I would figure out what is going to happen on a circuit, and then I could analogically work my way back to the mechanical system. If you think about it, it is really a brilliant thing by some engineers years ago to figure that out.

The systems sequence, she argued, was a conscious attempt to help students cross disciplinary boundaries by thinking in terms of analogies and systems. Another faculty member corroborated the intentional use of content and instructional methods to help students make these connections, describing how faculty would first solve a problem as a mechanical engineer would, "and then we would say, 'By the way there is an alternative approach of doing it' and demonstrate that." The same approach is used to connect theoretical knowledge. He gave the following example:

For instance, Kirchoff's current law that is nothing more than the conservation of charge. In mechanical systems that would just be conservation of linear momentum. It is exactly the same principle applied in different fields. Oftentimes students may think that they are completely different laws at work, but they are exactly the same. So we make such analogies throughout. We point out to the students that by the way this is exactly what you 
saw in chemical engineering. This principle is what you have learned in physics or what not. So we really try to integrate everything a student had learned here at Harvey Mudd.

Although "multidisciplinary" using our original definition, the systems sequence can be viewed as a step in the process of helping students integrate knowledge across courses, thus contributing to the development of HMC students' interdisciplinary competence.

Other case study institutions focused on engaging students in interdisciplinary thinking from their first year by providing introductory engineering or design courses or linking courses thematically to help students see the connections among disciplines. Some argued that the design project, even if not conducted via interdisciplinary teamwork, would achieve similar goals. An aerospace engineer, for example, noted that the capstone design project makes it clear to students that they "need to be able to converse with the people who are doing... working on the different parts of the airplane." When asked by the interviewer if students from other fields provided the opportunity for conversation, he replied, "I can't say that they formally do." Rather, he argued, students become aware of the need as a result of the instruction provided by the "industry-focused person teaching the capstone design course." According to the conceptualization of interdisciplinary competence that guided this study, this attention to building awareness can be viewed as a step toward disciplinary appreciation and thus interdisciplinary competence.

In others programs, instructional strategies such as collaborative or project-based learning ensured students from different programs worked together, presumably creating greater opportunities for interaction and cross-fertilization of ideas. Team-based design courses were a common venue for this type of interaction. At Virginia Tech, one faculty member reported teaching sections of his design courses in an interdisciplinary manner for ten years by giving a subset of students in his program the opportunity to work with students in industrial engineering:

Right now we have a 300 seat large class that meets once a week and twice a week in smaller workshops -42 seat workshops. I took one or two of those small workshops and had them working with industrial design students in collaborative teams. ... I try to keep that sort of interdisciplinary focus and try to have it something that is relevant and humancentered.

A project-based course at ASU asked students to integrate their knowledge in a design-build-test project based on a bungee jump object - an egg dropped from 55 feet from the top of one of the university's stadiums. The instructor explained,

And so they had to use some of the physics they'd learned about forces, free body diagrams, mass, acceleration, velocity, position. They had to know about air resistance. They had to know about damping in the bungee cord, those sorts of mechanical and material things. Mathematics, we had them solve the different set-up and solve the differential equations for the motion of the egg falling out of a bungee cord. And it's actually a very complicated problem because part way through, when the egg is far enough along, the bungee cord becomes taut and then adds an additional force. And so add a force to a differential equation that turns on and turns off. From an analytical point of view, it's extremely complicated, but in doing this with an Excel spreadsheet and doing it numerically, it's very straightforward to add it to it. 
In addition, the students were given the design specifications for the deceleration for the egg and proximity to the ground, and other engineering considerations. Videotapes of the motions of the eggs were use as catalysts for discussions of theories and equations and students were assessed on their writing skills as they reported on their work.

At Harvey Mudd, the sophomore lab course for engineers also takes a hands-on, project-based approach using a rocket design as the integrative mechanism. The professor who co-designed the course explained that it was originally a set of fourteen unrelated lectures and experiments from different engineering disciplines. After a number of years, one of the professors, a civil engineer, revised the course by adding a field-based component in which students instrumented the overpasses of a local highway to understand vibration responses. The course, however, had recently been completely revised and now included a final project requiring students to fly fully instrumented model rockets. All the disciplines of engineering are represented and each of the lab experiments is geared toward understanding some aspect of the rocket.

Other extended opportunities for multi- or interdisciplinary learning exist at the case study institutions in the form of elective courses, minors, and double or dual majors. At MIT, a bioengineer recalled that long history of chemical engineering connections with the biological sciences resulted in the Institute's first interdepartmental minor for students who were interested in bioengineering. At the University of Michigan, a number of recently developed minors were the curricular vehicle for multi- and interdisciplinary learning. The 15-credit minor in multidisciplinary design, for example, requires students to engage in two cycles (at least one year) of design-build-test projects. One of the faculty members who helped build the minor explained that

The first [cycle] is meant to be introductory. There is a preparatory course requirement that is intended to broaden the student and prepare them for multidisciplinary activity. So there is a curricula requirement for them to get a course that is out of their program. So for example, our EE.... If we could take ME 250 that would be okay to broaden their perspective on design

His description of the curriculum suggests a process-orientation to multidisciplinary design, with an introductory design-build-test experience and coursework outside the major department that would prepare students for the multidisciplinary work to follow. When asked if these projects were similar to the experiences that students would get in design competitions, he responded in a way that suggested how the projects would become "truly" interdisciplinary:

We are interested in the students that want to change the world, too. So put the students in a setting that is truly interdisciplinary where they are.... There is EECS. There is mechanical. I mean and hopefully we are going to be able to pull in business or other areas depending on the project. Truly interdisciplinary, having them work together on a real, a real problem. Give them some experiences that honestly you can't teach in a classroom and honestly we hope that it will also motivate the classroom experience because now they understand why class A and class B are so important.

ABET's requirement that all engineering graduates develop the ability to work in multidisciplinary teams was frequently cited as a motivation for hands-on or project-based work. As we demonstrated earlier, while some engineers interpret multidisciplinary teamwork narrowly, by focusing on interactions among engineering majors, others defined it more broadly to include 
interactions with ideas, or students, from beyond engineering. In some cases, the jump to interdisciplinarity was viewed as additive; students from another major would provide the crossfertilization needed. In other cases, a real world-problem was viewed as the most important ingredient in building engineer's interdisciplinary competence.

\section{Integrating Engineering and Non-Engineering Knowledge}

At MIT faculty sought to integrate first-year courses in the sciences and humanities by using a common theme across courses. Harvey Mudd offers an interdisciplinary learning experience called the "Integrative Experience" or IE course. The dean of the college, a chemist, explained:

...the integrative experience is supposed to be taken when you are a junior or senior, and it explicitly looks at the integration of technical disciplines in society, or some issue. So for example, with a historian in science, I teach a course in science and religion. But there is a computer scientist who teaches a course in information management and the ethics of that. There is a mathematician who teaches a course in decision making, certainly biologists teach courses in bio-ethics and gene therapy. But there are all sorts of these courses. So [it is] one of the requirements for the students. Overall, from an educational point of view I think it was a huge success. Students get it, and it is part of the mission statement...

At ASU, a course called Innovation Space offers students opportunities to work with students in other engineering fields, as well as with students from industrial and graphic design and business. Similarly, the multidisciplinary design minor at Michigan was viewed as a flexible vehicle for interdisciplinary learning. The director of international programs in the College of Engineering at Michigan noted how the program could be molded to fit the needs of different faculty and students:

But we start talking with faculty and one of the specializations for this multidisciplinary design minor MDD is global health. Well lo and behold, this faculty member comes back to see me and says, well my field work is in Ghana, so if I want the students who are doing the global health specialty to spend a summer in Ghana, I said well, that is overseas experience and that is absolutely something that we can organize, could this be open to any student if they just want this rich experience but they don't plan to do the whole minor. But these happy accidents, and what is nice about it is the faculty that are going to try these new interdisciplinary kind of unconventional things have a lot of energy, so they are good to work with. So stuff happens.

\section{Linking Curricular and Co-Curricular Learning}

Many institutions offer competitions where students work on multi- or interdisciplinary teams on design projects. One critique of these competitions is that they do not reach all students; some students cannot afford to spend their time on such activities, perhaps due to family or work obligations. At the case study sites, student organizations were providing additional interdisciplinary opportunities for students with different interests and different circumstances. The entrepreneurship minor at UM, for example, spawned a student organization called MPowered which is similar to a consulting firm for students from all over the university who have the entrepreneurial spirit and an idea. For example, this online classified system brings business students and engineering students together to implement and then market their ideas. 
Another activity, called BlueLab, offered students interested in sustainability the opportunity to meet like-minded engineers, as well as students from outside engineering. As one student member noted, a student's major was not the motivating force. Similar student organization existed at the other case study sites, complimenting the curricular avenues that fostered interdisciplinary competence.

\section{Faculty Research as a Conduit for Interdisciplinary Learning}

Because our project focused on the undergraduate educational process, the majority of our interviews focused on curricular and instructional efforts to provide interdisciplinary experiences to students. In some of the case study sites, however, an emphasis on undergraduate research created opportunities for many students to engage in interdisciplinary study. At Harvey Mudd, where about 80 percent of all students participate in at least one undergraduate research experience before graduation, an engineering faculty member described the interactions of her undergraduate research team, which is attempting to tissue-engineer a cornea.

... we try and break that down into parts. There is your standard tissue engineering approach, there is your cell population and what it is doing, there is your scaffold and matrix that the cells live in, and then there is whatever -- signals, mechanical, chemical, electrical -whatever you want to impart to this thing to try to get it to do what you want it to do. So I give [the students] this big picture, and what we do every summer is we have teams of students, interdisciplinary teams working on each of the three stems. But there is overlap, right? So, for example, right now we have got a group of students who is working on a technique to electro-spin an aligned collagen matrix which replicates the kind of structure of the cornea. So they have to learn about the biology and try to figure out how to replicate it so material science stuff. And then you put cells on it, and then the cell teams helps them figure out what proteins those cells are expressing, aligned, versus unaligned, versus if you stress it, don't stress it. That kind of thing.

The faculty at HMC tended to be very aware of how pedagogy influences student learning. Many courses require students to work collaboratively on short- and long-term projects, and the engineering program requires an extended design course sequence of all students. Peer collaboration and peer teaching are encouraged and respected. The engineering professor quoted above talked about how this instructional approach benefits students:

One of the real strengths I think in the program that I run in terms of research is the educational value of having people come from different backgrounds and contribute to it in different ways and teach each other their different things. So that has been a big deal for me, and I will keep that going as long as I have interest from the students in doing that. I am not sure that going for a joint major in bioengineering is really going to help with that.

At ASU, one engineer explained how faculty research trickles down into educational opportunities for students, saying, "Interaction of the faculty for research projects is very common. So when that level of interaction happens there, you start getting graduate students first, then you can add in different projects that you can break them up into senior design projects for undergraduates." 
ASU's location, suggested another faculty member, enable industry interactions which, in turn, provided experiential and at least multidisciplinary learning opportunities for students: "we've got a lot of companies, lots of opportunities for our students to interact with local industries through these internships and experiential learning. And then that also affects - many of us have research contracts, we've got traditional NSF [grants] that we also do research with many of the companies as well."

\section{Conclusion}

When we began this study, we anticipated that our attempt to examine educational practices that lead to the development of interdisciplinary competence in undergraduate engineers would include some challenges. We imagined that once we settled on a clear set of definitions, these problems would be alleviated. They were not. Consistent with the findings of Lattuca $(2001)^{3}$, we found that engineers, like other faculty, held a variety of understandings of the term interdisciplinarity. The faculty and administrators we interviewed used the terms multidisciplinarity and interdisciplinarity and others, like cross-disciplinarity, interchangeably. The methodological questions this raised regarding whether exclude educational activities from consideration if they did not focus on the integration of disciplinary perspectives or include people or perspectives from fields outside engineering led us to further consider our definitions.

In examining the definitions we used for the study, we began to see how interdisciplinarity, which we defined at the integration of perspectives from inside and outside engineering, could be developed incrementally through activities that raised students' awareness of their own discipline (its strengths and limitations). From this vantage point we also recognized that multidisciplinary teams or projects, which we categorized as those activities that were conducted within engineering, were not necessarily failed examples of interdisciplinarity, but might be intentional, or unintentional, steps on the road to greater awareness of the disciplines, critical thinking, and perhaps eventually, interdisciplinary competence.

Moreover, our study participants' descriptions and discussions of multi- and interdisciplinary learning activities suggested a variety of educational outcomes (types of knowledge and skills) to be developed through different kinds of activities. These outcomes will depend in part on whether students' educational activities include interactions with faculty and/or students within or outside the discipline of engineering. Importantly, our data do not lead us to presume that every multidisciplinary activity described helps students develop this competence; instead the data provide ideas to consider as we build engineering programs that seek to instill in students interdisciplinary habits of thinking and problem solving.

Criterion 3.d of the EC2000 accreditation standards requires all engineering programs to ensure that their graduates develop the ability to work in multidisciplinary teams. Our findings, although not generalizable, suggest there will be considerable variation in engineering faculty and administrators' understandings of that criterion. The confusion in terms may be insignificant if faculty members have a clear sense of the learning outcomes they expect to result from different learning activities. For example, restricting engineering teams to engineers may be acceptable if the primary educational objectives are the development of students' understanding of the different fields within engineering or the development of basic teamwork skills. If the 
learning objective, however, is a greater appreciation of how engineering solutions impact local communities or the environment, how to interact effectively with individuals who define a problem very differently than you do, or how to manage a geographically dispersed and multinational team, then expanding those teams to include different disciplinary and nondisciplinary perspectives appears critical to success.

Several engineers that we interviewed suggested that integration of disciplinary perspectives occurs "naturally" in some fields that are "inherently interdisciplinary" (civil engineering, bioengineering, etc.). In some cases, the speaker seemed to assume that instructors need not cultivate interdisciplinary competence; students would "get it" by advancing through their academic programs. In some programs, this may be the case because the curricular and instructional approaches in place provide opportunities for students to think about the strengths and limitations of their discipline and others, consider the value that other disciplinary perspectives lend to engineering problems or research, or provide project-based activities that engage students in active integration of knowledge and conversation across disciplines. Purposeful integration of courses, such as the design or systems sequences, can help students connect what is learned in their courses, while out-of-class opportunities can encourage them to think about how the knowledge and skills from different disciplines could be used to solve engineering problems in industry and in their local and global communities. Without purposeful curricular designs and faculty collaboration across courses to ensure connections are made, it is unlikely that all students will "get it" and that all engineers will be well prepared to work effectively on teams where a variety of disciplinary viewpoints are not only represented but must be reconciled, synthesized, and leveraged.

\section{Bibliography}

${ }^{1}$ Klein, J. T. (1990). Interdisciplinarity: History, Theory, and Practice. Detroit, MI: Wayne State University Press.

${ }^{2}$ Kockelmans, J. (1979).Interdisciplinarity and Higher Education. University Park, PA: Pennsylvania State University Press.

${ }^{3}$ Lattuca, L. R. (2001). Creating Interdisciplinarity: Interdisciplinary Research and Teaching among College and University Faculty. Nashville, TN: Vanderbilt University Press.

${ }^{4}$ Organisation for Economic Co-operation and Development (1972). Interdisciplinarity: Problems of Teaching and Research in Universities. Paris: OECD.

${ }^{5}$ Repko, A. F. (2008). Interdisciplinary Research: Process and Theory. Thousand Oaks, CA: Sage.

${ }^{6}$ Borrego, M., Newswander, C., McNair, L. McGinnis, S. and Paretti, M. (2009). Using Concept Maps to Assess Interdisciplinary Integration of Green Engineering Knowledge. Advances in Engineering Education, 1 (3). Retrieved January 4, 2010 from http://advances.asee.org/vol01/issue03/05.cfm

${ }^{7}$ Drezek, K. M., Olson, D., and Borrego, M. (2008). Crossing Disciplinary Borders: A New Approach to Preparing Students for Interdisciplinary Research. Proceedings, 38th ASEE/IEEE Frontiers in Education Conference, Saratoga Springs, NY.

${ }^{8}$ McNair, L. D., Paretti, M. C., \& Kakar, A. (2008). Case study of prior knowledge: Expectations and identity constructions in interdisciplinary, cross-cultural virtual collaboration. International Journal of Engineering Education, 24(2).

${ }^{9}$ Newswander, L. K., \& Borrego, M. (2009). Engagement in two interdisciplinary graduate programs. Higher Education 58 (4), 551-662. 
${ }^{10}$ Richter, D. M., \& Paretti, M. C. (2009). Identifying barriers to and outcomes of interdisciplinarity in the engineering classroom. European Journal of Engineering Education, 34(1), 29-45.

${ }^{11}$ National Academy of Engineering. (2004). The Engineer of 2020: Visions of Engineering in the New Century. Washington, DC: National Academies Press.

${ }^{12}$ ABET. Engineering Criteria 2000. Baltimore, MD: Author.

${ }^{13}$ Miller, R. C. (1982). Varieties of interdisciplinary approaches in the social sciences. Issues in Integrative Studies, $1,1-37$.

${ }^{14}$ Klein, J. T. (1996). Crossing Boundaries: Knowledge, Disciplinarities, and Interdisciplinarities. Charlottesville: University Press of Virginia.

${ }^{15}$ Richards, D. G. (1996). The meaning and relevance of "synthesis" in interdisciplinary studies. The Journal of Education, 45 (2), 114-28).

${ }^{16}$ Newell, W. H. (1998). Interdisciplinarity: Essays from the Literature. NY: College Entrance Examination Board.

${ }^{17}$ Klein, J. T. (1993). Blurring, Cracking, and Crossing: Permeation and the Fracturing of Discipline. In E. MesserDavidow, D. Sylvan, \& D. Shumway (Eds.), Knowledges: Historical and Critical Studies of Disciplinarity (pp. 185211). Charlottesville: University Press of Virginia.

${ }^{18}$ Heckhausen, H. (1972). Some approaches to interdisciplinarity: discipline and interdisciplinarity. In L. Apostel, G. Berger, A. Briggs, \& G. Michaud (Eds.), Interdisciplinarity: Problems of Teaching and Research in Universities (pp. 83-89). Paris: OECD.

${ }^{19}$ Jantsch, E. (1972). Toward Interdisciplinarity and transdisciplinarity in education and innovation. In L. Apostel, G. Berger, A. Briggs, \& G. Michaud (Eds.), Interdisciplinarity: Problems of Teaching and Research in Universities (pp. 97-121). Paris: OECD.

${ }^{20}$ Klein, J.T. and Newell, W. T. (1996). “Advancing Interdisciplinary Studies.” In J G. Gaff and J. L. Ratcliff (Eds.) Handbook of the Undergraduate Curriculum: A Comprehensive Guide to Purposes, Structures, Practices, and Change. San Francisco: Jossey-Bass.

${ }^{21}$ Piaget, J. (1972). The epistemology of interdisciplinary relationships.. In L. Apostel, G. Berger, A. Briggs, \& G. Michaud (Eds.), Interdisciplinarity: Problems of Teaching and Research in Universities (pp.127-39). Paris: OECD.

${ }^{22}$ Hirsh Hadorn. G., Hoffmann-Riem, H., Biber-Klemm, S., Grossenbacher-Mansuy, W., Joye, D., Pohl, C., Wiesmann, U. and Zemp, E. Handbook of Transdisciplinary Research. Netherlands: Springer.

${ }^{23}$ Gibbons, M., Limoges, C., Nowotny, H, Schwartzman, S., Scott, P. and Trow. M (1994). The New Production of Knowledge: The Dynamics of Science and Research in Contemporary Societies. Thousand Oaks, CA: Sage.

${ }^{24}$ Bogdan, R. C., \& Biklen, S. K. (2006). Qualitative research for education: An introduction to theory and methods. (5 $5^{\text {th }}$ edition). Boston: Allyn \& Bacon.

${ }^{25}$ Denzin, N. K, \& Lincoln, Y. S. (2000). Handbook of Qualitative Research (2 ${ }^{\text {nd }}$ edition). Thousand Oaks, CA: Sage.

${ }^{26}$ Lattuca, L. R., Terenzini, P. T., \& Volkwein, J. F. (2006). Engineering change: A study of the impact of EC2000, Final report. Baltimore, MD: ABET, Inc.

${ }^{27}$ Yin, R. K. (2009). Case Study Research: Design and Methods ( $4^{\text {th }}$ edition). Thousand Oaks, CA: Sage.

\footnotetext{
${ }^{\mathrm{i}}$ An interdiscipline is defined as a field that resulted from interdisciplinary activities but that has, over time, become like a discipline in that it has its own perspectives and professional community. Biochemistry is an example of an interdiscipline that has become well established while the field of women's studies is, arguably, in a transitional phase (see Repko, 2005, p. 52) 5 .
} 